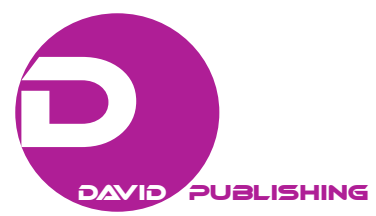

\title{
Students’ Attitudes Toward Modes of Evaluation at the University $^{1}$
}

\author{
Mordechai Miron \\ Tel Aviv University, Tel Aviv, Israel
}

\begin{abstract}
The purpose of the study was to determine the attitudes of Israeli students towards different modes of evaluation. The sample consisted of 346 undergraduate students who were enrolled in different faculties. The instrument used in the study was a questionnaire which aimed to establish students' preferences for three different modes of evaluation: The dada revealed that essay tests were the most common mode of evaluation while objective tests were the least frequent. The students favored the three types of evaluation, papers scored the highest, objective tests were less preferred and essay tests scored the lowest. The analysis of the data indicated that there were significant differences among students’ attitudes from different faculties towards each mode of evaluation.
\end{abstract}

Keywords: modes of evaluation, students’ attitudes, essay tests, objective test, written papers

\section{Introduction}

Since the mid-1960's student influence on decisions affecting university life has increased in many countries, particularly in the area of instruction. Their influence on academic decision-making was partially generated through standard questionnaires, in which students rate the effectiveness of university instruction. However, these evaluation measures rarely included information on student perceptions of the relative merits of various test procedures (Mabry, 1997).

Students have firm attitudes toward different modes of testing and evaluation. These attitudes should not be ignored, because there can be little doubt that test performance is influenced to some extent by students' positive or negative perceptions regarding the tests they take. Murchan (1989) concluded that the format of testing has a great impact on how and what teachers teach and students learn. Research findings revealed that student's perceptions of assessment significantly influence their approach to learning and studying (Struyven, Dochy, \& Janssens, 2018).

Different types of tests also tend to determine the students' approach to learning. Drew (2001) found significant differences in students' perceptions of essay tests as compared to their perceptions of multiple-choice formats.

Zeidner (1987) found that students prefer the multiple-choice format to an essay type examination in almost all dimensions of his inventory (perceived difficulty, anxiety, complexity, success expectancy, and feeling at ease). There was only one dimension in which students thought that essay exams were more appropriate: namely, for the purpose of representing one's knowledge in the subject matter (Zeidner, 2014).

\footnotetext{
${ }^{1}$ In this paper, evaluation, testing, and assessment are used interchangeably.

Mordechai Miron, Ph.D., professor (retired), School of Education, Tel Aviv University.
} 
Traub and MacRury (1990) found similar results. According to Boud and Falchikov (2007), student's likes and dislikes for particular test modes have changed very little in the recent years. Multiple-choice items were in the past and still are generally recognized by students as the most widely applicable and useful mode of evaluation. Similarly, they maintained that testing practices and ultimate decision-making processes among professors have not changed extensively.

The purpose of the present study was to determinate the extent of use of different modes of testing on the university level and to explore the attitudes of Israeli students towards these testing modes. Three questions were examined empirically:

1. To what extent were different modes of testing used at the university?

2. What were the students' attitudes towards these modes?

3. Where the students' attitudes towards evaluation modes related to the academic faculties in which they were enrolled?

\section{Method}

\section{Sample}

The population consisted of 346 undergraduate students enrolled in six different faculties in Tel-Aviv University: Exact Sciences $(N=24)$, Medicine $(N=57)$, Life Sciences $(N=62)$, Social Sciences $(N=68)$, Humanities $(N=100)$, and Law $(N=35)$. In order to obtain the largest possible number of students who had experienced various modes of evaluation, the students who participated in the study were selected on the basis of a proportional sampling of second-year students in compulsory courses.

\section{Instruments and Procedure}

The questionnaires used in this study aimed to investigate three different type of evaluation commonly used at the university: objective tests (multiple-choice questions), essay-type tests, and written papers. In order to ascertain the frequency of use, the students were asked to rate each of the three evaluation modes on a 3-point scale (“used very frequently", “used occasionally”, and "seldom used”). In order to determine student preferences, a 66-item questionnaire was devised, consisting of three 22-item subscales (objective tests, essay-type tests, and written papers) rated on a 5-point-Likert scale from "Strongly Agree = 1" to "Strongly disagree $=5$ ”, with scores for each subscale ranging from 22 to 110 .

The instrument was devised to incorporate statements for and against the different types of evaluation. A score of 66 represented a neutral attitude toward the evaluation mode, whereas a score lower than 66 indicated a favorable attitude and a score higher than 66 indicated a negative attitude. The questionnaires were administered during class periods, and respondents were guaranteed anonymity.

\section{Results}

\section{Question One: To What Extent Were Different Modes of Tests Used at the University?}

Students' reports on the frequency of the existing modes of evaluation are presented in Table 1. The data indicated that essay tests were the most commonly used mode of evaluation, whereas objective test were the least frequently used.

\section{Question Two: What Were the Students' Attitudes Toward These Modes?}

The students' attitudes toward the three evaluation modes were measured by the three subscales in the 
questionnaire. Table 2 presents the means, standard deviations, and 95\% confidence intervals ${ }^{2}$.

Table 1

Frequency (in Percentages) of Existing Evaluation Modes $(N=346)$

\begin{tabular}{llll}
\hline Mode of evaluation frequency & Essay test & Objective test & Written paper \\
\hline Used very frequently & 72 & 16 & 16 \\
Used occasionally & 22 & 36 & 55 \\
Seldom used & 6 & 48 & 29 \\
\hline
\end{tabular}

Table 2

Means, Standard Deviations, and 95\% Confidence Intervals for the Means of the Three Subscales

\begin{tabular}{llll}
\hline Mode of evaluation & Mean & $S D$ & $95 \%$ Confidence interval for means \\
\hline Essay test & 63.1 & 14.3 & $61.6-64.6$ \\
Objective test & 57.6 & 14.3 & $56.0-59.0$ \\
Written paper & 55.9 & 13.4 & $54.5-57.3$ \\
\hline
\end{tabular}

The results revealed a favorable attitude toward each of the three modes. The mean of each subscale was lower than the neutral score, even when examining the 95\% confidence interval. Though students held favorable attitudes toward all three types of evaluation, papers scored the highest, objective testes were less preferred, and essay tests scored the lowest.

\section{Question Three: Were the Students' Attitudes Toward Evaluation Modes Related to the Academic Faculties in Which They Were Enrolled?}

Three separate one-way analyses of variance (ANOVAs) were conducted to compare the attitudes of students from different faculties toward each of the three evaluation modes. The analyses revealed significant differences between faculties for students' attitudes toward essay test $(F 345=2.55), p<0.01)$, the objective test $(F 345=5.93), p<0.1)$, and written papers $(F 345=3.78), p<0.1)$. Table 3 presents the means and standard deviations of the scores on each of the three evaluation mode subscales, by faculty.

Table 3

Means and Standard Deviations of the Three Subscales for the Different Faculties

\begin{tabular}{|c|c|c|c|c|c|c|c|}
\hline \multirow{2}{*}{$\begin{array}{l}\text { Mode of evaluation } \\
\text { frequency }\end{array}$} & \multicolumn{3}{|c|}{ Essay test } & \multicolumn{2}{|c|}{ Objective test } & \multicolumn{2}{|c|}{ Written paper } \\
\hline & $N$ & $M$ & $S D$ & $M$ & $S D$ & $M$ & $S D$ \\
\hline Exact Sciences & 24 & 58.5 & 18.4 & 58.7 & 10.7 & 57.1 & 11.1 \\
\hline Medicine & 57 & 60.8 & 13.0 & 50.4 & 16.6 & 60.3 & 20.0 \\
\hline Life Sciences & 62 & 67.3 & 13.3 & 59.4 & 14.6 & 54.8 & 9.2 \\
\hline Social Sciences & 68 & 60.9 & 11.0 & 63.4 & 13.5 & 54.4 & 11.4 \\
\hline Humanities & 100 & 61.9 & 14.0 & 57.5 & 12.8 & 54.1 & 11.1 \\
\hline Law & 35 & 64.3 & 13.8 & 57.3 & 12.4 & 60.8 & 14.1 \\
\hline
\end{tabular}

The attitudes of medical students toward essay tests were identical to those of students in the social sciences. With regard to the objective tests, humanities students resembled law students. Similar attitudes toward written papers were evidenced by students enrolled in life sciences, social sciences, and the humanities.

The order of preferences differed from faculty to faculty. In the humanities, the order, from most preferred to least, was papers, objective tests, and essay tests, whereas in the social sciences, the order was papers, essay

\footnotetext{
${ }^{2}$ The 95\% confidence interval for a mean gives the limits within which we can be 95\% confident that the populations mean falls.
} 
test, and objective tests. Medical students preferred objective tests and did not strongly differentiate between the other two evaluation modes. In most faculties, essay tests were the least preferred mode of evaluation.

\section{Discussion and Conclusions}

The purpose of the study was to investigate the frequency of use of three different modes of evaluation in an Israeli university and to examine the attitudes of university students toward these modes: essay tests, objective tests, and written papers. Essay tests were reported to be the most common mode of evaluation encountered by the students, whereas objective testing was the mode experienced least frequently. The predominance of essay tests may reflect university professors' reliance on familiar evaluation modes, thus, perpetuating testing practices to which they were exposed during their own studies. Without specific training on grading and assessment, educators draw primarily on their own experiences as students in determining the grading policies and practices they employ (Stiggins, 2005). Most university professors master their area of academic expertise but know very little about instruction and evaluation. This breach must be viewed within the context of the crisis visited upon higher education, arising both from the lack of coordination between instruction and research activities and from the lack of adequate training for and empirical recognition of university positions. Instructors in all disciplines have an important role in offering students the best in instruction and in evaluating the resultant learning in the most responsible manner possible. After all, the professor has the final say on such indicators of academic success as students' grades (Struyven, Dochy, \& Janseens, 2005). This task is even more critical for those who are involved in staff development at the university. Young instructors, upon receiving their teaching certification, will perpetuate in their classrooms certain conventions that will influence testing practices for future generations of university students.

Students in this sample indicated a favorable attitude toward each of the three modes of evaluation. The mean for each attitude subscale was moderate and lower than the neutral cut-off point, indicating the students' conformity and satisfaction with the existing modes of evaluation. More than 40 years ago, Shapira and Etzioni-Halevy (1973) noted that the Israeli student tended to conform and had a generally moderate approach toward the university. Students approved of the university's structure, functions, and instructional and evolutional methods. The present study substantiated these findings at least with regard to the evaluation modes. Future research should investigate other samples and instruments in order to validate the current results.

Though students favored all three types of evaluation, papers scored highest, followed by objective tests, and essay tests scored lowest. These results do not corroborate Zeinder's (1987) and Boud and Falchikov's (2007) findings that students preferred mostly multiple-choice items. The differences may stem from the testing experiences to which students in the different samples had previously been exposed.

The findings indicate that students in different faculties differ in their attitudes toward modes of evaluation. It seems that studying within the framework of a scientific discipline and of a certain professional orientation may influence students' attitudes and expectations, including their attitudes toward the different modes of evaluation (Kellaghan \& Madaus, 2003).

This study may offer university professors valuable information in the area of testing. Testing practices should receive further cautions exploration. Although students' perceptions may be erroneous, students are the consumers of our instructional processes, and thus, cannot be disregarded. If students have a negative attitude toward a particular type of test, that attitude in itself may tend to invalidate the test. Furthermore, our testing instruments and subsequent grading policies have far-reaching effects on future generations of students. 


\section{References}

Boud, D., \& Falchikov, N. (Eds.). (2007). Rethinking assessment for higher education: Learning for the longer term. London: Routledge.

Drew, S. (2001). Students perceptions of what helps learn and develop in education. Teaching in Higher Education, 6(3).

Kellaghan, T., \& Madaus, G. (2003). External (public) examination. In T. Kellaghan and D. I. Stufflebean (Eds.), International handbook of education evaluation (Vol. 9, pp. 577-600). Dordrecht: Kluwer.

Mabry, I. (Ed.) (1997). Evaluation and the post-modern dilemma. Greenwich, CT: JAI Press.

Murchan, D. P. (1989, March 28-30). Essay versus objective achievement testing in context of large-scale assessment programs. Paper presented at The Annual Meeting of the National Council on Measurement in Education, San Francisco, CA.

Shapira, R., \& Etzioni, H. E. (1973). Who is the Israeli student? Tel Aviv: Am Oved. (in Hebrew)

Stiggins, R. J. (2005). Communicating with report cards. In R. J. Stiggins (Ed.), Student-involved assessment for learning (pp. 275-319). Upper Saddle River, NJ: Pearson Education.

Struyven, K., Dochy, E., \& Janseens, S. (2005). Students’ perceptions about evaluation and assessment in higher education: A review. Assessment \& Evaluation in Higher Education, 30(4), 325-347.

Traub, R. E., \& MacRury, K. (1990). Multiple-choice vs. Free-response in the testing of scholastic achievement. In K. Ingenkamp and R. S. Kager (Eds.), Test und tends 8: Jahrbuch derpadagogischen diagnostik (pp. 128-159). Weinheim: Beltz Verlag.

Zeidner, M. (1987). Essay versus multiple-choice type classroom exams: The student's perspective. Journal of Educational Research, 80(6), 352-358.

Zeidner, M. (2014). Text anxiety. In P. Emmelkamp and T. Ehring (Eds.), Wiley handbook of anxiety disorders (pp. 581-595). London: Wiley-Blackwell. 